\title{
Green synthesis and characterization of silver nanoparticles using Cydonia oblong seed extract
}

\author{
Faria Zia $^{1} \cdot$ Nida Ghafoor $^{1} \cdot$ Mudassir Iqbal $^{2} \cdot{\text { Saliha } \text { Mehboob }^{3}}^{3}$
}

Received: 8 October 2015/Accepted: 3 January 2016/Published online: 22 January 2016

(c) The Author(s) 2016. This article is published with open access at Springerlink.com

\begin{abstract}
The green synthesis of nanoparticles has emerged as a cost-effective and environmentally benign technique. The present study describes the synthesis of silver nanoparticles (Ag-NPs) using a seed extract of $C y$ donia oblonga. The conditions were optimized by adjusting $\mathrm{pH}$, temperature, time and amount of seed extract. The nanoparticles produced were characterized by different techniques, namely UV-visible spectroscopy, Fourier transmission infrared spectroscopy (FTIR), X-ray diffraction (XRD) and scanning electron microscopy. The formation of Ag-NPs was confirmed by UV-visible spectroscopic analysis. FTIR analysis was performed to identify the biomolecules, which played a key role in the reduction of $\mathrm{Ag}^{+}$ions. XRD confirmed that the silver nanoparticles possessed face-centered cubic structure. The green chemistry approach has proven that Ag-NPs can be synthesized by using plant extract in which biomolecules effectively act as capping and reducing agent.
\end{abstract}

Keywords Ag-nanoparticles · Green synthesis - Cydonia oblonga

Mudassir Iqbal

mudassir.iqbal@sns.nust.edu.pk

1 Department of Chemistry, Kinnaird College for Women Lahore, Lahore, Pakistan

2 Department of Chemistry, School of Natural Sciences, National University of Sciences of Technology (NUST), H-12, Islamabad, Pakistan

3 University of Agriculture Faisalabad, Sub Campus Burewala, Vehari, Pakistan

\section{Introduction}

Nanoparticles are clusters of microscopic particles ranging from 1 to $100 \mathrm{~nm}$ in size and exhibit properties on the basis of morphology, size and distribution (Kostoff et al. 2007). Nanoparticles act as a bridge between bulk material and atomic structure. As the size of the particles approaches the nanoscale, the characteristics of the materials change and the percentage of atoms on the surface becomes significant. The principle parameters of NPs are "size, shape, surface characteristics and inner structure" (Kaddour 2013). The special features and properties of nanoparticles like catalytic property, optical property, surface-enhanced Raman scattering (Yi et al. 2013) and chemical strength (Forough and Farhadi 2010) are attributed to high fraction of surface atoms and quantum confinement (Dunn 2004; Feynman 1960; Forough and Farhadi 2010).

Metallic nanoparticles such as $\mathrm{Cu}, \mathrm{Ag}$ and $\mathrm{Au}$ exhibit distinctive characteristic properties by coupling with the electromagnetic radiations and causing surface plasmon (Ghorbani et al. 2011a, b). This coupling interaction can be tuned to get the desired optical properties of metallic nanoparticles. The maximum absorption occurs at surface plasmon resonance. Silver nanoparticles among the metallic nanoparticles have distinctive characteristics, e.g., good conductivity, catalytic activity, chemical stability and antibacterial, anti-viral, antifungal anti-inflammatory activities. They are widely used in photo-catalysis, biology, medicine, optics and electronics (Vodnik et al. 2010; Sharma et al. 2014). In chemical reduction method for the synthesis of Ag-NPs, organic and inorganic reducing agents such as polyvinyl pyrrolidone, $\mathrm{NaBH}_{4}, \mathrm{~N}_{2} \mathrm{H}_{4}$ and sodium citrate, in controlling the growth of NPs and prevention from aggregation, are used. Chemicals used in this method pose a risk to the environment and biotic life as they are toxic and harmful (Awwad and Salem 2012). 
Hence for the synthesis of stable metal nanoparticles, safer, inexpensive, reliable and green approaches with controlled shape and size have been developed. Green synthesis offers improvement over other methods, i.e., synthetic, chemical or using micro-organisms, as it is reported to be cost-effective, environmentally friendly and non-toxic to the environment and can be used for largescale synthesis (Ghorbani et al. 2011a, b). The green chemistry method is based on the mechanism of plantassisted reduction due to the presence of phytochemicals (Pavani et al. 2012). The main phytochemicals involved are flavones, aldehydes, terpenoids, ketones, carboxylic acids and amides. In the present work, a seed extract of Cydonia oblonga was used as reductant and stabilizer for silver nanoparticles. These seeds are a rich source of proteins, lipids, crude fiber, oleic, palmitic, linoleic and stearic acids, phenol and flavonoids (Silva et al. 2005).

\section{Experimental}

\section{Preparation of seed extract}

$10 \mathrm{~g}$ of Cydonia Oblonga seeds were washed thoroughly and soaked in $500 \mathrm{~mL}$ of distilled water overnight and blended for $5 \mathrm{~min}$ in a kitchen blender. Pure seed extract was separated by reiterated vacuum filtration and then stored at lower temperature to prevent fungal growth.

\section{Preparation of silver nitrate solution}

$0.01697 \mathrm{~g}$ of $\mathrm{AgNO}_{3}$ was dissolved in $100 \mathrm{~mL}$ distilled water to produce $1 \mathrm{mM}$ solution of $\mathrm{AgNO}_{3}$.

\section{Preparation of 0.1 M NaOH solution}

$0.4 \mathrm{~g}$ of $\mathrm{NaOH}$ was dissolved per $100 \mathrm{~mL}$ of distilled water to prepare $0.1 \mathrm{M} \mathrm{NaOH}$ solution and further used to adjust the $\mathrm{pH}$ values in different experiments.

\section{Synthesis of silver nanoparticles}

\section{Silver nanoparticles synthesis at varying concentration}

Different amounts of seed extracts, i.e., 5, 10, 15, 20, 25 and $30 \mathrm{~mL}$, were incubated in round bottom flasks in different experiments with $1 \mathrm{mM}$ aqueous $\mathrm{AgNO}_{3}$ solution $(30 \mathrm{~mL})$. With vigorous stirring, the extract was added dropwise to the $\mathrm{AgNO}_{3}$ solution and the total volume was made up to $60 \mathrm{~mL}$ by addition of distilled water. The color changed from light yellow to dark brown after continuous stirring for $4 \mathrm{~h}$. Ag-NPs synthesis was confirmed by UV/ visible spectra at $350-700 \mathrm{~nm}$.

\section{Silver nanoparticles synthesis at varying temperatures}

To optimize the temperature, the reaction mixtures were allowed to react separately at 50,70 and $90{ }^{\circ} \mathrm{C}$, respectively, with continuous stirring for 3-4 h.

\section{Silver nanoparticles synthesis at varying $P H$}

The solutions were prepared at constant concentration $\left(15 \mathrm{~mL}\right.$ seed extract) at a temperature of $70{ }^{\circ} \mathrm{C}$ in both acidic and basic media to synthesize silver nanoparticles at varying $\mathrm{pH}$, ranging from 3 to 11 . The $\mathrm{pH}$ was adjusted to lower values by dropwise addition of glacial acetic acid and to higher values by dropwise addition of sodium hydroxide.

\section{Silver nanoparticles synthesis at varying stirring times}

To study the stirring time effect, on silver nanoparticles synthesis, the bio-reduced silver nanoparticles solution was run on a UV-visible spectrophotometer at regular time intervals ( $0 \mathrm{~s}, 30,60,90,120$ and $150 \mathrm{~min})$ and $\lambda_{\max }$ was noted.

\section{Characterization}

The formation of Ag-NPs was monitored by a UV-Vis spectrophotometer (Perkin-Elmer, Lamda 35, and Germany) in the wavelength range between 350 and $700 \mathrm{~nm}$. Before and after the formation of silver nanoparticles, dried seed extract was subjected to Fourier transmission infrared spectroscopy (FTIR) analysis through the $\mathrm{KBr}$ pellets method. The spectra were measured in the wavelength range $500-4000 \mathrm{~cm}^{-1}$ at $1 \mathrm{~cm}^{-1}$ resolution. The solution of Ag-Nps was subjected to centrifugation at 10,000 revolutions per minute for $40 \mathrm{~min}$. The resulting mixture was then air dried to get purified Ag-NPs. X-ray diffractometer (Bruker AXS D8 Advance) was used to study the structure of metallic nanoparticles.

Hitachi S-4500 SEM was used for SEM analysis. A thin film of the sample was prepared by drying a small amount of the sample solution on a copper stub in a dust-free environment.

\section{Results and discussion}

\section{Visual observation}

In accordance with literature studies, Ag-NPs solution has dark brown color. The color of the Cydonia oblonga seed 

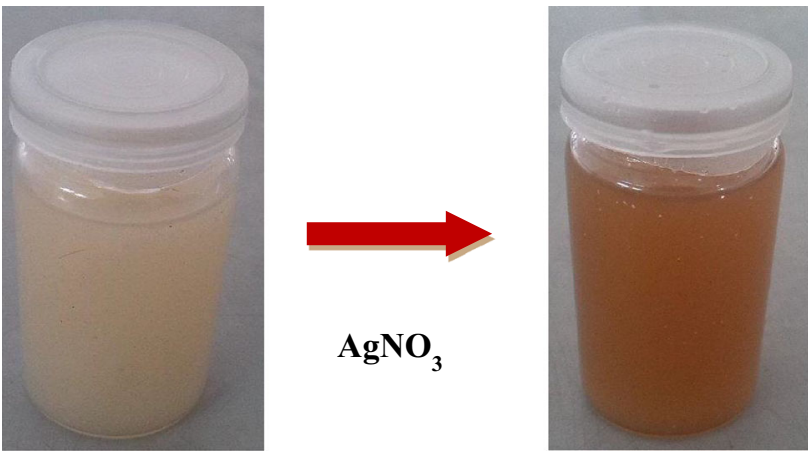

Fig. 1 Visual observation of the solution before bio-reduction (left) and after bio-reduction (right)

extract was pale yellow (Fig. 1) before its treatment with silver nitrate solution, but after the reaction it turned to dark brown (Fig. 1), indicating the formation of Ag-NPs due to reduction of silver ions by active molecules present in the extract. This color is attributed to surface plasmon resonance, which is a size-dependent property of NPs (Nair et al. 2014; Desai et al. 2012).

\section{UV-visible spectroscopy}

Figure $2 \mathrm{a}$ shows the reactions at 50,70 and $90{ }^{\circ} \mathrm{C}$. UV spectra indicated that the wavelength was higher at lower temperature, but the wavelength shifted to a lower value at higher temperature resulting in the formation of smaller silver nanoparticles at higher temperature, whereas at higher wavelength the size of silver nanoparticles increased. The maximum absorbance was observed at 462, 432 and
$421 \mathrm{~nm}$ at 50,70 and $90{ }^{\circ} \mathrm{C}$, respectively. It means at higher temperature, reactants are consumed rapidly, resulting in the formation of smaller nanoparticles (Ibrahim 2015).

The optimum temperature was found to be $70{ }^{\circ} \mathrm{C}$, showing a characteristics band for silver nanoparticles with monodispersity. The aggregation of silver nanoparticles results in electronically coupled metal particles which have different SPR than individual particles; so, SPR shows a red shift with the appearance of a second band at about $580 \mathrm{~nm}$ (http://www.sigmaaldrich.com/materials-science/ nanomaterials/silver-nanoparticles.html).

The optimum concentration of the extract was found to be $15 \mathrm{~mL}$ in $1: 1$ with the extract at $70{ }^{\circ} \mathrm{C}$, as indicated $\mathrm{n}$ Fig. 2a.

Figure $2 \mathrm{c}$ also indicates the effect of $\mathrm{pH}$ on the growth of silver nanoparticles. The color of the solution was observed at varying $\mathrm{pH}$ values. The highest color intensity of the reaction mixture was observed at $\mathrm{pH} \mathrm{9.} \mathrm{As} \mathrm{the}$ nanoparticles are not developed in extremely acidic media (Ibrahim 2015), there was no reaction at a $\mathrm{pH}$ value equal to 3, but monodispersive silver nanoparticles were obtained at $\mathrm{pH}$ equal to 9. The SPR peaks revealed that the rate of reduction increased with time.

The stirring time effect on the synthesis of silver nanoparticles is shown in Fig. 2c. The color intensity and monodispersity increased with stirring time (Ibrahim 2015). The appearance of surface plasmon resonance peak (SPR) at a wavelength range of 400-450 nm corresponds to Ag-NPs which absorb radiations intensely at a wavelength of $410 \mathrm{~nm}$ due to the transition of electrons.

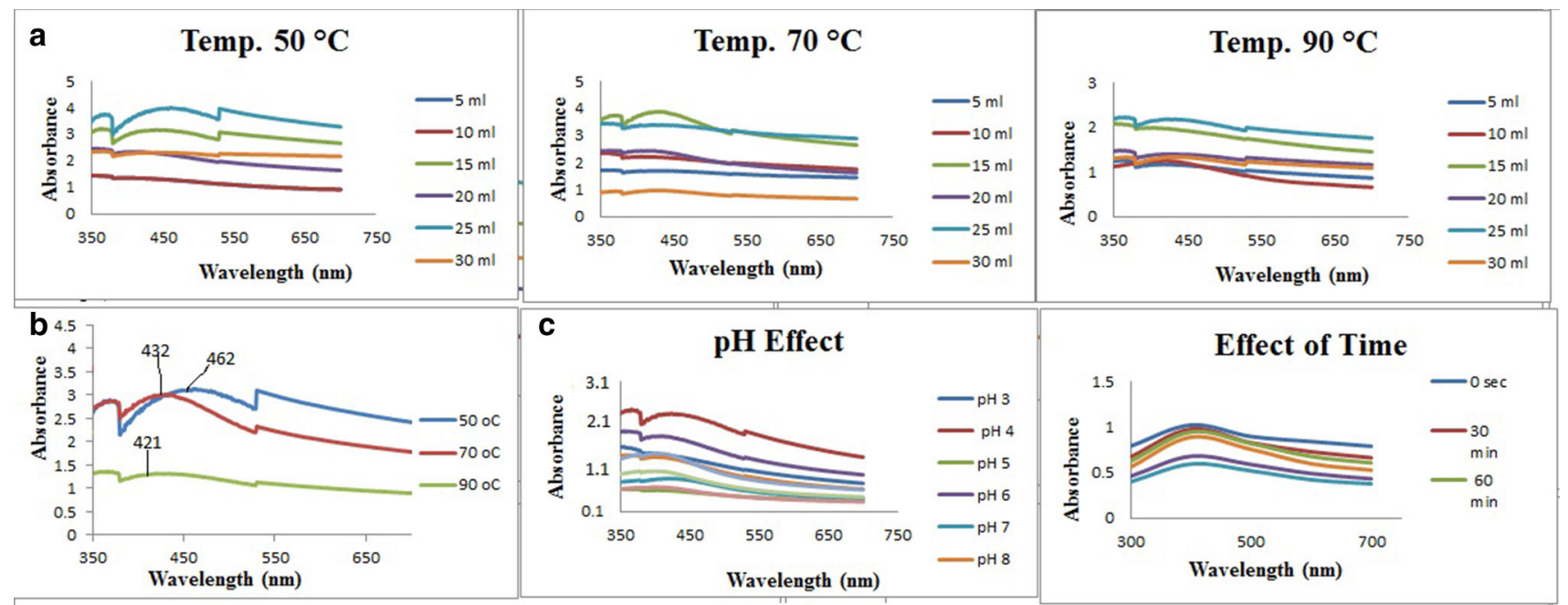

Fig. 2 a UV-visible spectrum of different concentrations of Cydonia oblonga seeds extract with silver nanoparticles at 50, 70 and $90{ }^{\circ} \mathrm{C}$. b Effect of temperature on resonance wavelength (UV spectra indicated that wavelength was higher at lower temperature, but the wavelength shifted to a lower value at higher temperature resulting in the formation of smaller silver nanoparticles). c Effect of $\mathrm{pH}$ (left), effect of time (right) 
Fig. 3 a FTIR spectra of Cydonia oblonga seed extract. b FTIR spectra of silver nanoparticles

Fig. 4 Diffractogram showing the intensity of peaks as a function of the diffraction angles
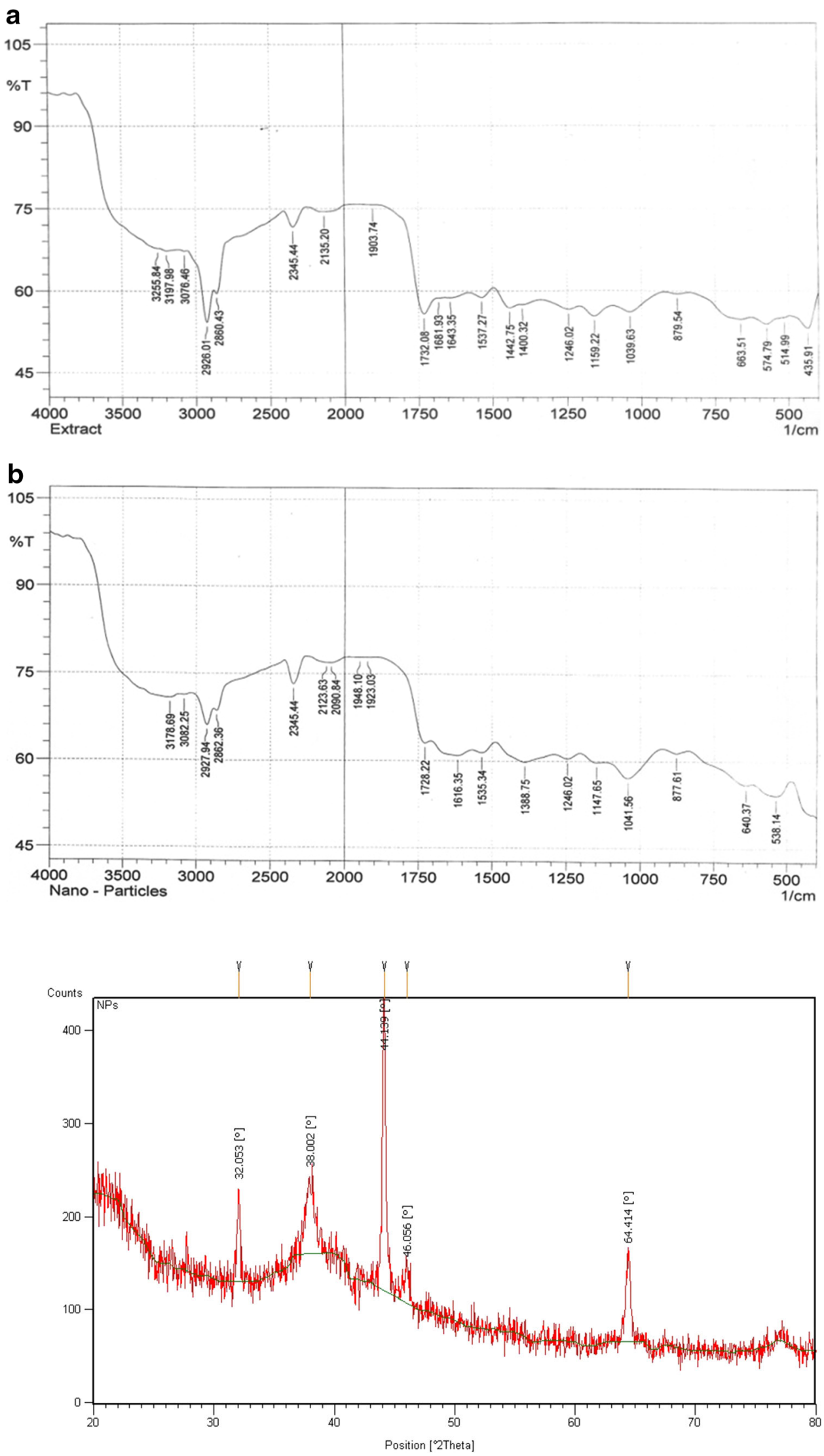


\section{Infrared spectroscopy}

The FTIR spectrum of the seed extract of Cydonia oblonga is shown by Fig. 3a. The absorption bands at 3255.84, 3197.98 and $3076.46 \mathrm{~cm}^{-1}$ are associated with $\mathrm{NH}$ (amide) and $\mathrm{OH}$ (alcohol) stretching. The peaks at 2926.01,

Table 1 The experimental diffraction angle and standard diffraction angle

\begin{tabular}{ll}
\hline $\begin{array}{l}\text { Experimental diffraction } \\
\text { angle }(2 \theta)\end{array}$ & $\begin{array}{l}\text { Standard diffraction } \\
\text { angle }\end{array}$ \\
\hline 44.139 & 44.3 \\
\hline
\end{tabular}

Table 2 Diffraction angle, average size, $d$-spacing and FWHM or full width at half maximum

\begin{tabular}{llll}
\hline $\begin{array}{l}\text { Diffraction } \\
\text { angle }\left(^{\circ}\right)\end{array}$ & FWHM & $\begin{array}{l}\text { Diffraction } \\
\text { plane }(\mathrm{hk} 1)\end{array}$ & $\begin{array}{l}\text { Particle } \\
\text { size }(\mathrm{nm})\end{array}$ \\
\hline 44.139 & 0.08024 & 200 & 38 \\
\hline
\end{tabular}

$2860.43 \mathrm{~cm}^{-1}$ are associated with anti-symmetric and symmetric stretching of $\mathrm{CH}_{2}$, respectively. The peak for the carbonyl group was found at $1732.08 \mathrm{~cm}^{-1}$.

The FTIR spectrum of silver nanoparticles is also shown in Fig. 3b. The peak for $\mathrm{NH}$ stretching was obtained at $3178.60 \mathrm{~cm}^{-1}$. The peaks at 3082.25 , $2862.36 \mathrm{~cm}^{-1}$ are associated with symmetric $\mathrm{CH}_{2}$ stretching. The peak at $2927.94 \mathrm{~cm}^{-1}$ is associated with $\mathrm{CH}_{2}$ stretching. The peak at $2123.63 \mathrm{~cm}^{-1}$ indicated $\mathrm{C} \equiv \mathrm{C}$ stretching and that at $1948.10 \mathrm{~cm}^{-1}$ was associated with allenes $(\mathrm{C} \equiv \mathrm{C} \equiv \mathrm{C})$. The peak for the carbonyl group was obtained at $1728.22 \mathrm{~cm}^{-1}$. The carbonyl groups proved the presence of flavanones or terpenoids that are adsorbed on the surface of metal nano-sized particles by interaction through $\pi$-electrons in the carbonyl groups in the absence of sufficient concentration of chelating agents. It was also confirmed that the carbonyl group from the protein and amino acid had stronger ability to bind with metal nanoparticles or act as capping and stabilizing agents (Veeraputhiran 2013).
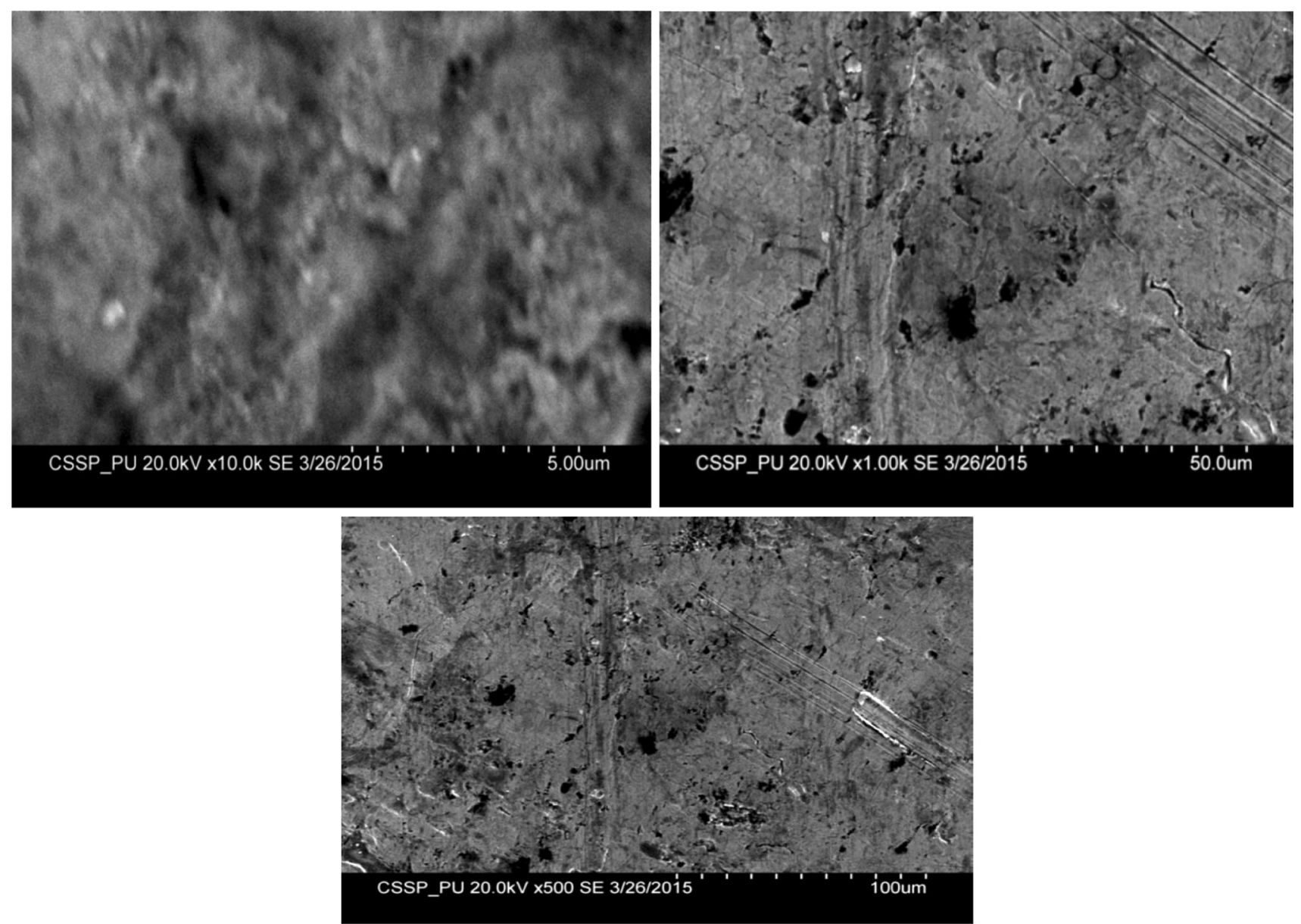

Fig. 5 SEM images of silver nanoparticles 


\section{XRD analysis}

\section{Peak indexing}

Peak indexing of silver nanoparticles is shown in Fig. 4.

\section{Diffraction angle}

The diffraction angles (Experimental and Standard) are given in Table 1.

\section{Particle size calculation}

X-ray diffraction (XRD) pattern showed the number of Bragg's reflections at diffraction $(2 \theta)$ angles $32.053^{\circ}$, $38.002^{\circ}, 44.109^{\circ}, 46.056^{\circ}$ and $64.414^{\circ}$, corresponding to planes $111,200,300$ and 220, respectively, which indicated that spherical silver nanoparticles are crystalline in nature (Ibrahim 2015) with face-centered cubic structure (fcc). The obtained data were compared with the "database of Joint committee on Powder Diffraction Standards (JCPDS) file No. 04-0783" (Lim et al. 2011). Comparison between standard diffraction angle and experimental diffraction angle revealed that both are in good agreement with each other (Table 2). The average size of particles was found to be $38 \mathrm{~nm}$ (Table 2). The peak broadening and noise may be due to the presence of various crystalline biological macromolecules in the plant extract. Experimental conditions might have affected the nucleation and growth of the crystal nuclei, causing the smaller size of nanoparticles. Broader peaks seem to serve as evidence to this argument (Krishnaraj et al. 2012).

\section{Scanning electron microscopic (SEM) analysis}

The morphology and size of silver nanoparticles was revealed by scanning electron microscopic (SEM) analysis. SEM images showed that Ag-NPs have been formed and $\mathrm{Ag}^{+}$ions have been completely consumed (Fig. 5).

\section{Conclusion}

Green synthesis is an effective way to synthesize silver nanoparticles due to its eco-friendly, simple, cost-effective and efficient protocol. The present study included the production of environmentally benign Ag-NPs using $C y$ donia oblonga seeds extract, in which biomolecules acted as both capping and stabilizing agents. Reduction of silver nitrate to silver nanoparticles was confirmed by UV-visible spectrophotometer, FTIR, XRD and SEM techniques.
Hence, nanoparticles can be synthesized by avoiding hazardous chemicals and adopting the green protocol.

Open Access This article is distributed under the terms of the Creative Commons Attribution 4.0 International License (http:// creativecommons.org/licenses/by/4.0/), which permits unrestricted use, distribution, and reproduction in any medium, provided you give appropriate credit to the original author(s) and the source, provide a link to the Creative Commons license, and indicate if changes were made.

\section{References}

Awwad AM, Salem NM (2012) Green synthesis of silver nanoparticles by mulberry leaves extract. Nanosci Nanotechnol 2(4):125-128

Desai R, Mankad V, Gupta SK, Jha PK (2012) Size distribution of silver nanoparticles: UV-visible spectroscopic assessment. Nanosci Nanotechnol Lett. 4:30-34

Dunn SW (2004) Applications of nanoparticles in biology and medicine. J Nanobiotechnol 2(3):1-6

Feynman R (1960) There's plenty of room at the bottom. J Eng Sci. 23(5):22-36

Forough M, Farhadi K (2010) Biological and green synthesis of silver nanoparticles. J Eng Environ Sci 4(7):281-287

Ghorbani HR, Safekordi AA, Attar H, Rezayat Sorkhabad SM (2011a) Biological and non-biological methods for silver nanoparticles synthesis. J Chem Eng Sci and Res Branch 25(3):317-326

Ghorbani HR, Safekordi AA, Attar H, Sorkhabad SM (2011b) Biological and non-biological methods for silver nanoparticles synthesis. J Chem Eng Sci Res Branch 25(3):317-326

Ibrahim HM (2015) Green synthesis and characterization of silver nanoparticles using banana peel extract and their antimicrobial activity against representative microorganisms. J Rad Res App Sci 8(3):265-275

Kaddour N (2013) No laws in nanoland: how to reverse the trend? The French Example. J Nanotechnol Environ 30(2):486-522

Kostoff RN, Koytcheff RG, Lau CGY (2007) Global nanotechnology research literature overview. Technol Forecast Soc Change 74:1733-1747

Krishnaraj C, Ramachandran R, Mohan K, Kalaichelvan PT (2012) Optimization for rapid synthesis of silver nanoparticles and its effect on phytopathogenic fungi. Spectrochim Acta A Mol Biomol Spectrosc. 93(5):95-99

Lim GK, Fujii K, Harris KDM, Apperley DC (2011) Structure determination from powder X-ray diffraction data of a new polymorph of a high-density organic hydrate material, with an assessment of hydrogen-bond disorder by Rietveld refinement. Cryst Growth Des 11(12):5192-5199

Nair AS, Vinila VS, Issac S, Jacob R, Mony A, Nair HG, Rajan S (2014) Studies on nano crystalline ceramic superconductor $\mathrm{LaZrYBaCa} \mathrm{Cu}_{3} \mathrm{O}_{11}$ at three different temperatures. Chem Mater Sci 4(2):126-133

Pavani KV, Sunilkumar N, Grayathramma K (2012) Plants as ecofriendly nanofactories. J Biosci 6(1):1-6

Sharma G, Sharma AR, Kurian M, Bhavesh R et al (2014) Green synthesis of silver nanoparticle using Myristica fragrans (Nutmeg) seed extract and its biological activity. Digest J Nanomater Biostructures. 9(1):325-332

Silva BM, Andrade PB, Ferreres F, Seabra RM, Oliveira MB, Ferreira MA (2005) Composition of quince (Cydonia oblonga Miller) 
seeds: phenolics, organic acids and free amino acids. Nat Prod Res 3:275-281

Veeraputhiran V (2013) Bio-catalytic synthesis of silver nanoparticles. Int J Chem Tech Res. 5:2555-2562

Vodnik VV, Božanic DK, Bibic N, Šaponjić ZV (2010) Optical properties of shaped silver nanoparticles. J Nanosci Nanotechnol $8: 1-5$
Yi S, Sun L, Lenaghan SC, Wang Y, Chong X, Zhang Z, Zhang M (2013) One-step synthesis of dendritic gold nanoflowers with high surface-enhanced Raman scattering (SERS) properties. RSC Adv 3(26):10139-10144 